\title{
Opiophobia: A Barrier to Pain Management
}

\author{
Ibtihal M. Alattas, MD \\ Department of Emergency Medicine, Faculty of Medicine \\ King Abdulaziz University, Jeddah, Saudi Arabia
}

\section{Correspondence \\ Dr. Ibtihal M. Alattas \\ P.O. Box 80215, Jeddah 21589 \\ e.M: ialattas@kau.edu.sa \\ Submission: 16 Apr. 2016 \\ Accepted: 24 May 2016}

\section{Citation}

Alattas IM. Opiophobia: A barrier to pain management. JKAU Med Sci 2016; 23 (3): 1-7. DOI: 10.4197/Med. 23.3.1

\begin{abstract}
Opiophobia is the physicians' irrational fear of prescribing opioids for patients with severe pain. It's one of the major reasons for many patients to not receive adequate analgesia (oligoanalgesia). It's an old phenomenon that still persists in both developed and developing countries with different rates. This is an unsystematic literature review of studies that have been written about opiophobia since 1960 using Google Scholar, PubMed and EBSCO to search for the following terms: opiophobia, oligoanalgesia and necrophobia. Studies included were review articles and surveys studies. We found that the three main reasons for opiophobia are concern over addiction, concern over serious side effects (mainly respiratory depression) and concern over legal consequences. These consequences, such as being sued, result from serious side effects masking or delaying the diagnosis. Lack of knowledge about pain management was another factor among young physicians and interns. As a result, many patients are not adequately treated for severe pain. Physicians prescribe lesser dosages than required and nurses administer even lesser dosages than the physicians prescribed. To tackle such problems, it's important to know the causes. Education, clarification of the myths and increasing the physicians' and nurses' awareness about pain management is a critically important step especially for new physicians and interns.
\end{abstract}

\section{Keywords}

Opiophobia; Oligoanalgesia; Pain management; Necrophobia

\section{Introduction}

$P$ ain is one of the top reasons for many patients to visit the emergency department (ED). According to U.S. National Health Statistics, approximately $20 \%$ of U.S. adults have visited the ED in the last year ${ }^{[1]}$. Some studies suggest the prevalence of pain in ED's around the world to be between $52-79 \%{ }^{[2]}$. Despite advances and innovation in medical research and technology, emergency department (ED) patients are still suffering under treatment for their pain; whether they are patients with acute pain or cancer patients with breakthrough attacks. There is no excuse for not relieving a patient's pain. Leaving a patient in pain is unethical; indicates poor clinical care and poor patients' satisfaction; leads to increased utilization of medical services and decreases patients' follow up; and can complicate the progress of some diseases ${ }^{[3,4]}$.

Opiophobia has a few definitions but it's the physician's irrational fear of prescribing opioids to patients who need $\mathrm{it}^{[5]}$. Opiophobia is one of the main reasons for oligoanalgesia, which is inadequate pain management for patients suffering from pain. Unfortunately different people from different countries, who suffer the same pain/pathology, receive various 
management due to different health care providers' beliefs and culture about pain management. In 1973, Mark and Sachar described opiophobia as "For many physicians these drugs may have a special emotional significance that interferes with their rational use" ${ }^{\prime \prime 6]}$. Motov and $\mathrm{Khan}^{[7]}$ in 2008 identified many causes for opiophobia such as: regulatory concerns, drug seeking behavior, concern of addiction, lack of follow up and fear of masking symptoms of acute illness ${ }^{[7,8]}$.

In 2000, the Joint Commission on Accreditation of Healthcare Organizations (JCAHO) and the American Pain Society (APS) released a new standard for pain management which is described in six standards chapters: Patients' Rights and Ethics, Assessment of Persons with Pain, Care of Persons with Pain, Education of Persons with Pain, Continuum of Care and Improvement of Organization Performance ${ }^{[9]}$.

Oligoanalgesia is not a new phenomenon. In 1973, a survey of 37 patients found the average meperidine dose that was given was $90 \mathrm{mg}$ per day- even though the $\mathrm{mg} / \mathrm{kg}$ dose for meperidine is $50-100 \mathrm{mg}$ and can be repeated every 1-3 hour as needed (not to exceed 600 $\mathrm{mg} / 24$ hour). Another survey in two New York teaching hospitals showed misconception of meperidine; many physicians underestimate the dose, overestimate the side effect and exaggerate the addiction risk ${ }^{[6]}$.

Even though drug misuse, especially of narcotics, has been documented and currently is prevalent what has been called "opioid epidemic" in the United States - in this paper we shed light on another type of misusing narcotics: failure to treat patients with severe pain due to concerns of addiction or adverse effects ${ }^{[10]}$. Health care providers' beliefs and behaviors differ from country to country. While this paper focuses on opiophobia globally and more specifically in the developing world, where more patients are deprived from opioids due to the phobia, we still have to be vigilant about different phenomena such as opioid overuse. In addition to the fear of addiction and serious side effects, many physicians are concerned about legal consequences of prescribing such medication. This would differ also based on the legal structure and the laws of the country.

\section{Methods}

We conducted a literature review using the term opiophobia in PubMed, Google Scholar and ESCO Medline search. The following other terms were used to control for variation in vocabularies: necrophobia, oligoanalgesia and inadequate pain management. We included studies published from 1960 and after, to explore the history of opiophobia in hospitals. The search was limited to studies published in English language only. The search was not limited to specific study design, but literature reviews and survey studies were predominant studies in this review. This paper focuses on physicians - including interns. Studies on nurses and other health care providers - physician assistants or registered nurses - were excluded. We aim to explore the physicians' knowledge, attitude and behavior toward prescribing opioids to patients in acute pain by reviewing our search results.

\section{Results}

In 1973, a survey on two teaching hospitals in New York found junior physicians (interns) prescribed less than required for pain relief to patients who were in severe distress due to their pain ${ }^{[6]}$. In the same study, when researchers asked physicians what they were trying to achieve by prescribing opioids, $100 \%$ of physicians stated that they want to relieve the pain completely. But from surveying the patients and assessing their pain, the physicians' goals were not reached. Furthermore, they prescribed on average $66 \mathrm{mg}$ every 4 hours of meperidine which in average total would be about $390 \mathrm{mg}$ per day. But, what the patients were actually receiving per day was only an average of $103 \mathrm{mg}$, even though many patients were still in severe or moderate distress due to persistent pain ${ }^{[6]}$. The researchers in the previous study ${ }^{[6]}$ went further to explore the physicians' attitude and behavior toward prescribing opioids and they formulated a hypothetical question where a patient in severe pain receives $100 \mathrm{mg}$ of meperidine but is still in pain. About $60 \%$ of the physicians stopped at $100 \mathrm{mg}$ of meperidine and only $12 \%$ of them increased the dose above $100 \mathrm{mg}$, even though research studies suggest that $100 \mathrm{mg}$ of meperidine is at the therapeutic dose and many patients need a higher dose. The physicians were further asked why wouldn't they increase the dose beyond the $100 \mathrm{mg}$, $40 \%$ stated that it wouldn't relieve the pain further and $60 \%$ of them stated that a dose above $100 \mathrm{mg}$ would increase risk of serious side effects ${ }^{[6]}$.

In 1992, a survey showed that around 50\% of the emergency physicians involved were uncomfortable in managing elderly patient with pain due to inadequate training and lack of continuous education ${ }^{[11]}$. Multiple government representatives from different European countries agreed that physicians should work together 
to relieve cancer pain and those patient should not live with pain where relief is possible ${ }^{[12]}$. Since 1999, Jones et al. ${ }^{[13]}$ reported that a single 4 hours didactic presentation to Emergency Medicine residents on pain management resulted in a significant improvement of patient pain management. Also, opiophobia decreased by $20 \%$ in medical residents after attending didactic sessions about pain management ${ }^{[14]}$.

A study in Taiwan showed that only 39\% of physicians would prescribe opioids for pain and $86 \%$ were concerned about tolerance development and $72 \%$ overestimated the likelihood of addiction ${ }^{[15]}$. Guidelines on pain management and regulatory statutes on treating pain from the American College of Emergency Physicians (ACEP), the Joint Commission on Accreditation of Healthcare Organization $s^{[16]}$, and the American Pain Society ${ }^{[17]}$, stated that health providers still struggle to resolve the problem of "oligoanalgesia" in EDs ${ }^{[7]}$. In 2004, Rupp and Delaney suggested that adequate pain treatment can be achieved by changes in medical education, changes in medical practice and changes in health policy to make pain management a high priority through establishing policies, guidelines and measuring practice outcomes ${ }^{[18]}$.

Not only adults are suffering from oligoanalgesia but even children despite the evidence of its safety use. Goldman and his colleagues proved this in reviewing the charts of more than 500 children with abdominal pain and they found only $9 \%$ received opioids and $77 \%$ of the opioids given were below the recommended dose ${ }^{[19]}$. In 2009, Verloo et al. ${ }^{[20]}$ described the perception of the physician and nurses about morphine and found that most of them were not using morphine due to legal problems and $70 \%$ of the physicians did not use it out of fear of secondary respiratory depression as a side effect. Multiple studies in the United States have shown that only $52 \%$ of patients with pain receive assessment and only $75 \%$ received analgesia ${ }^{[19]}$.

Researchers from Italy reported that many patients in the EDs are suffering from pain with no adequate pain management ${ }^{[21]}$. In France, a multi-center study in 50 different EDs showed that only $51 \%$ of patients who suffered from pain received analgesia and morphine was used in only $9 \%$ of those patients who suffer severe pain ${ }^{[22]}$ The same study found that more than $20 \%$ of patients who presented with pain were discharged from the ED despite having persistent pain ${ }^{[22]}$. In the Eastern region of Saudi Arabia, a study found that only $25 \%$ of the patients who presented with pain during a three-month period received pain medication and
$25 \%$ of these patients who presented with pain were discharged without prescription ${ }^{[23]}$. The elderly as well tend to receive lower doses of morphine in general and they tend to be affected by oligoanalgesia, as they are less expressive about their pain ${ }^{[24]}$. Many surveys and medical record reviews showed that iatrogenic addiction is uncommon except in some patients with a history of substance abuse and some psychiatric disorders.

\section{Discussion}

Opiophobia is not a new phenomenon and it has been prevalent among junior physicians since the $1970 \mathrm{~s}^{[6]}$. It is considered to be the first reason of oligoanalgesia in cancer patients, around $20 \%-70 \%$ of physicians reported concerns about the side effects of opioids ${ }^{[25]}$. Despite the advances in medicine, medical innovations and the abundance of different types of pain medications with various routes and formulae, many patients in severe pain are still being left in hospitals suffering from pain or discharged home without pain medicine. With the recent increase of using prescription opioids and the recent opioid epidemic, policies and regulations tend to become stringent on opioid prescriptions. Physicians started to become aware of their habit in prescribing opioids especially for chronic patients. This new phenomenon might result in further bitter consequences on patients who are truly in pain. Discerning if the patient has a true pain or faked ones can be difficult at times, as pain is a subjective complaint by its nature and can be measured only by asking patients to estimate the severity.

Oligoanalgesia is a well-known phenomenon and it's predominant in the Emergency Department. From our literature review, we found that one of the main reasons for oligoanalgesia is opiophobia, which is a persistent phenomenon even though studies have shown the safety and the non-addictive property of opioids when given in the right dose for an acute pain indication. Yet, patients are still undertreated for pain and in some occasions are stigmatized by health care providers as having addictive behavior without objective evidence.

Physicians were concerned about prescribing opioids for addiction issues and side effects - mainly respiratory suppression. In addition to avoid these complications, they prescribe lesser doses than what is recommended. Healthcare providers who exaggerate the risk of addiction are more likely to under-dose patients - even in terminal cases of cancers. It seems 
like the physicians' behavior toward suspected addicts or healthy patients with pain persist when it comes to cancer patients ${ }^{[6]}$. Nurses were found to sometimes administer a less frequent dose than what the physicians had prescribed and asked patients to wait until the pain is severe - probably due to the same concerns: fear of addiction or side effects. Furthermore, they believe that parental opioids should be used for severe pain only ${ }^{[26]}$. These patients were suffering from disease conditions that were known to be extremely painful: rib fracture, renal colic, pulmonary embolism, pancreatic cancer, arterial occlusion of the leg, etc. When the researchers delved deeper in those cases which were undertreated and questioned the physicians for the reason behind not treating the pain adequately, they found the following: One of the patients was suffering from a terminal cancer stage that was complaining of depression and emotional disturbance in addition to having severe pain. The physician was reluctant to prescribe narcotics out of fear of addiction. When the patient's pain was addressed and treated well, the patient problem was resolved completely ${ }^{[6]}$. The second patient had an amputated leg and the intern did not treat him adequately because he presumed the patient displayed an addictive behavior. Later, the patient underwent surgical procedure to evacuate a large amount of pus from his stump; this was indicating the source of his true pain rather than addictive behavior ${ }^{[6]}$. Consequently, patients receive much less dose that wouldn't relieve their pain. Physicians need to evaluate pain based on objective methods such as the Pain Visual Scale, because pain is a symptom not a sign.

Although in the study's results section ${ }^{[6]}$ many physicians stated that they wouldn't increase the opioid dose as it's unlikely to produce further pain relief, but in reality meperidine and many other opioids have no ceiling effect ${ }^{[27]}$. In addition to giving a lesser dose than required, and patients receiving a lesser dose than prescribed, physicians tend to prescribe opioids at longer duration intervals than suggested in many research studies ${ }^{[6]}$. For instance, morphine was prescribed every 6-8 hours rather than 2-4 hours.

Another misbelief the physicians have is to overlook the withdrawal symptoms in patients treated with opioids for long periods of time. With a longer period of opioid use, withdrawal symptoms might appear such as rhinorrhea and sleep disturbance, but many physicians underestimate the risk of withdrawal symptoms ${ }^{[6]}$.
Although in this paper we shed light earlier more on meperidine because it was researched early in 1973, we are not endorsing meperidine as a first of choice opioid as it has a more euphoric effect and higher addiction rate. Other opioids, such as morphine, might be a safer option than meperidine.

The Joint Commission on Accreditation of Healthcare Organizations (JCAHO) along with the American Society of Pain Medicine released new guidelines in response to the widespread oligoanalgesia that affected thousands of patients who suffer from severe pain.

Physicians' lack of knowledge, especially junior ones, contributed greatly to opiophobia and oligoanalgesia. Part of the solution is to introduce educational content in medical school and residency training programs. Unrealistic opiophobia among physicians and the general public hinders the use of effective medication that can improve the quality of life for many patients ${ }^{[28]}$. Recently worldwide there was a doubling pattern in opioid analgesia use between 2001 2003 and 2011-2013; despite that, some countries still report opiophobia - including the developed countries - at a different level ${ }^{[5]}$. Despite opiophobia being the most important barrier for opioid use, this problem can be resolved. Physicians lack of knowledge about pain medications usually lead to unrealistic opiophobia but good education is able to change the attitude, beliefs and subsequently correct their behaviors.

Emergency departments create a peculiar setting where patients need to be treated soon and disposition is required as long as the patient is stabilized and has a treatment plan. In addition to that, many patients present to ED as new patients, where physicians have no former knowledge about the patients; many patients can't state exactly their pain as they are in critical condition; and last but not least the fast pace in the emergency setting prohibits appropriate assessment at times. Therefore, emergency physicians might not be able to adequately assess the patients' pain, reassess after giving pain medication or discern the patients who are truly in pain from the drug seekers. Emergency medicine physicians need to consider pain as a true emergency and treat it as such. But at the same time emergency physicians need to be aware of different behavior in patients with chronic pain and to strike a balance between risks and benefits of prescribing opioid analgesics ${ }^{[7]}$. Because of increased pain prevalence and increasing number of ED patients 
complaining of pain, ED physicians need to be experts in acute pain management and need to have their skills and knowledge robust and up to date. Emergency Medicine physicians need to know how to efficiently assess patients pain according to objective measures and offer pain management even if patients do not ask for pain medicine ${ }^{[29]}$.

Legal issues also influence physicians when prescribing pain medicine. This varies from country to country, city-to-city and even one hospital to another. In Saudi Arabia, this is apparent as we have many expatriate physicians who might be banned from travel in case medical lawsuit is raised against them. This also puts the patients on the risk of practicing Defensive Medicine, where physician's decision aims to protect him- or herself from possible legal consequences from the patient regardless of other aspects in treatment. Physicians' prescription behavior also varies based on their geographical location as opiophobia differ from place to place and legal complexities differ as well. But generally speaking, patients - especially cancer patients - in the developing countries are receiving much less pain medicine than patients in developed countries $^{[30]}$.

\section{Conclusion}

Opiophobia is an old phenomenon that persists even though some research has shown that the risk of addiction and respiratory depression is exaggerated especially in acute care settings. Reasons for such phenomenon are concern of addiction, side effects and legal consequences. These reasons differ from place to place based on healthcare providers' beliefs and attitudes. To reduce such phenomenon that is causing many patients - especially patients with cancer and bone fractures - to still suffer severe pain while the medications are available requires educating physicians about pain management, educating nurses about the importance of delivering the correct dose and educating hospitals on how to check the prevalence of Opiophobia in their facility. Because people differ in respect to their knowledge and behavior toward opioid use in pain management, further research work needs to be done in the same geographical location where researchers are interested in exploring the phenomena.

\section{Conflict of Interest}

The author has no conflict of interest.

\section{Disclosure}

The author did not receive any type of commercial support either in forms of compensation or financial for this study. The author has no financial interest in any of the products or devices, or drugs mentioned in this article.

\section{Ethical Approval}

Obtained.

\section{References}

[1] Gindi RM, Black LI, Cohen RA. Reasons for Emergency Room Use Among U.S. Adults Aged 18-64: National Health Interview Survey, 2013 and 2014. Natl Health Stat Report 2016; (90): 1-16.

[2] Berben SA, Meijs Th Fau - van Dongen RTM, van Dongen Rt Fau - van Vugt AB, van Vugt Ab Fau - Vloet LCM, Vloet Lc Fau - Mintjes-de Groot JJ, Mintjes-de Groot Jj Fau - van Achterberg T, van Achterberg T. Pain prevalence and pain relief in trauma patients in the Accident \& Emergency department. Injury 2008; 39(5): 578-585

[3] Fosnocht DE, Swanson ER, Barton ED. Changing attitudes about pain and pain control in emergency medicine. Emerg Med Clin North Am 2005; 23(2): 297-306.

[4] Muntlin A, Gunningberg L, Carlsson M. Patients' perceptions of quality of care at an emergency department and identification of areas for quality improvement. J Clin Nurs 2006; 15(8): 1045-1056.

[5] Berterame S, Erthal J, Thomas J, Fellner S, Vosse B, Clare P, Hao W, Johnson DT, Mohar A, Pavadia J, Samak AK, Sipp W, Sumyai V, Suryawati S, Toufiq J, Yans R, Mattick RP. Use of and barriers to access to opioid analgesics: a worldwide, regional, and national study. Lancet 2016; 387(10028): 1644-1656.

[6] Marks RM, Sachar EJ. Undertreatment of medical inpatients with narcotic analgesics. Ann Intern Med 1973; 78(2): 173181.

[7] Motov SM, Khan AN. Problems and barriers of pain management in the emergency department: Are we ever going to get better? J Pain Res 2008; 2: 5-11.

[8] Hill Jr CS. The barriers to adequate pain management with opioid analgesics. Semin Oncol 1993: 20(2 Suppl 1): 1-5.

[9] Phillips DM. JCAHO pain management standards are unveiled. Joint Commission on Accreditation of Healthcare Organizations. JAMA 2000; 284(4): 428-429.

[10] Dart RC, Severtson SG, Bucher-Bartelson B. Trends in opioid analgesic abuse and mortality in the United States. N Engl J Med 2015; 372(16): 1573-1574. 
[11] McNamara RM, Rousseau E, Sanders AB. Geriatric emergency medicine: a survey of practicing emergency physicians. Ann Emerg Med 1992; 21(7): 796-801.

[12] Zenz M, Willweber-Strumpf A. Opiophobia and cancer pain in Europe. Lancet 1993; 341 (8852): 1075-1076.

[13] Jones JB. Assessment of pain management skills in emergency medicine residents: the role of a pain education program. J Emerg Med 1999; 17(2): 349-354.

[14] Scott E, Borate U, Heitner S, Chaitowitz M, Tester W, Eiger G. Pain management practices by internal medicine residents--a comparison before and after educational and institutional interventions. Am J Hosp Palliat Care 2008; 25(6): 431-439.

[15] Ger LP, Ho ST, Wang JJ. Physicians'knowledge and attitudes toward the use of analgesics for cancer pain management: a survey of two medical centers in Taiwan. J Pain Symptom Manage 2000; 20(5): 335-344.

[16] Gallagher RM. Physician variability in pain management: are the JCAHO standards enough? Pain Med 2003; 4(1): 1-3.

[17] Fosnocht DE, Heaps ND, Swanson ER. Patient expectations for pain relief in the ED. Am J Emerg Med 2004; 22(4): 286288.

[18] Rupp T, Delaney KA. Inadequate analgesia in emergency medicine. Ann Emerg Med 2004; 43(4): 494-503.

[19] Goldman RD, Narula N, Klein-Kremer A, Finkelstein Y, Rogovik AL. Predictors for opioid analgesia administration in children with abdominal pain presenting to the emergency department. Clin J Pain 2008; 24(1): 11-15.

[20] Verloo H, Kabengele EM, Ferreira M, Rapin C-H, Chastonay P. [Opiophobie: état des lieux auprès des soignants à Beira Interior au Portugal.] Douleur et Analgésie 2009; 22(3): 186-195.

[21] Ripamonti C, Valle A, Peruselli C, Pessi MA, Prandi C. [Project "Hospital without pain": analysis of the Italian situation before the law 38]. Assist Inferm Ric 2011; 30(2): 95-99.

[22] Gueant S, Taleb A Fau - Borel-Kuhner J, Borel-Kuhner J Fau - Cauterman M, Cauterman M Fau - Raphael M, Raphael M Fau - Nathan G, Nathan G Fau - Ricard-Hibon A, RicardHibon A. Quality of pain management in the emergency department: results of a multicentre prospective study. Eur J Anaesthesiol 2011; 28(2): 97-105.

[23] Rehmani RS. Pain practices in a Saudi emergency department. Saudi Med J 2010; 31(5): 539-544.

[24] Jones JS, Johnson K, McNinch M. Age as a risk factor for inadequate emergency department analgesia. Am J Emerg Med 1996; 14(2): 157-160.

[25] Jacobsen R, Sjogren P, Moldrup C, Christrup L. Physicianrelated barriers to cancer pain management with opioid analgesics: a systematic review. J Opioid Manag 2007; 3(4): 207-214

[26] McCaffery M Fau - Hart LL, Hart LL. Undertreatment of acute pain with narcotics. Am J Nurs 1976; 76(10): 15861591.
[27] [No authors listed]. Cancer pain relief: with a guide to opioid availability. $2^{\text {nd }}$ ed. WHO 1996. 1-70.

[28] Lipman AG. Does opiophobia exist among pain specialists? J Pain Palliat Care Pharmacother 2004; 18(2): 1-5.

[29] Singer AJ, Garra G, Chohan JK, Dalmedo C, Thode HC, Jr. Triage pain scores and the desire for and use of analgesics. Ann Emerg Med 2008; 52(6): 689-695.

[30] Kim YC, Ahn JS, Calimag MM, Chao TC, Ho KY, Tho LM, Xia ZJ, Ward L, Moon H, Bhagat A. Current practices in cancer pain management in Asia: a survey of patients and physicians across 10 countries. Cancer Med 2015; 4(8): 1196-204 


\title{
الهلع الأفيوني (الهلع من الأدوية الأفيونية): كعائق لتسكين الألم
}

\author{
ابتهال محمد العطاس \\ قسم الطواريء، كلية الطب، جامعة الملك عبدالعزبيز \\ جدة ـ المدلكة العربية السعودية الطبة
}

المستخلص. الهُع الأفيوني هو خوف الأطباء غير المبرر لوصف الأدوية الأفيونية للمرضى الذين يعانون من آلام حادة.

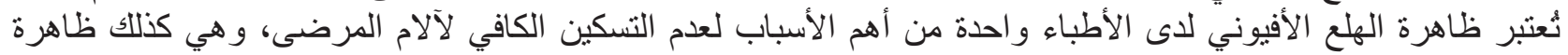

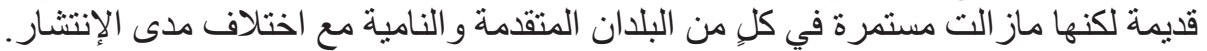

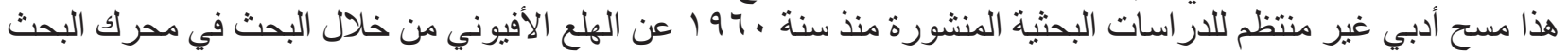

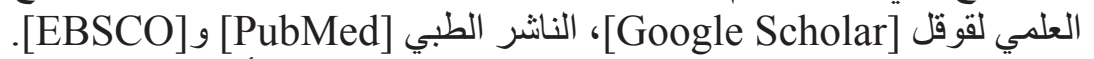
وقد تم استخدام المفردات التالية في محركات البحث: الهلع الأفيوني "opiophobia", هلع الأدوية المخدرة والتسكين غير

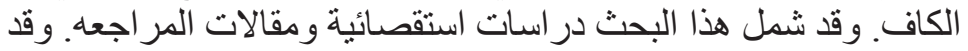

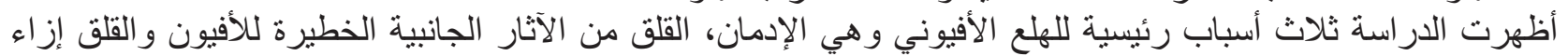

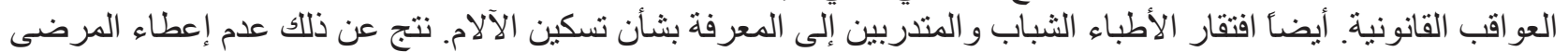

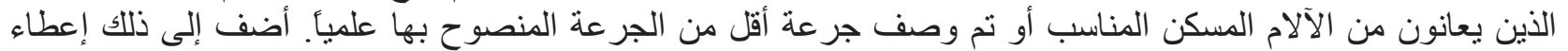

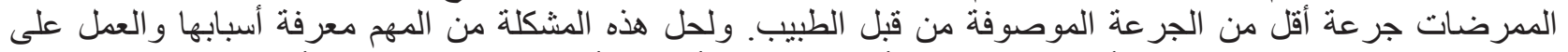

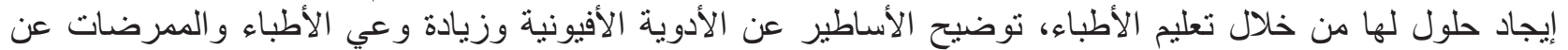
تسكين الألم. 